\title{
Strengthening of masonry structures using steel frames Angeliki Papalou*
}

\author{
Department of Renovation and Restoration of Buildings, T.E.I. of Patras, Greece \\ *Corresponding author E-mail: papalou@teipat.gr
}

\begin{abstract}
Many old masonry structures have not been maintained properly and have been left exposed to future seismic loading with only their exterior masonry walls. These structures can be strengthened using different techniques with the reversible ones being more appropriate for historic structures. The seismic behavior of masonry buildings left only with their perimeter walls and retrofitted using steel frames (a reversible technique) is investigated. The role of the connection of the steel frames with the masonry walls is analyzed. Linear elastic analysis is performed using the finite element method. The seismic resistance of the aforementioned buildings increases when there is a closed-spaced connection of the steel frame columns with the masonry walls. The connection of the masonry walls at the floor level with the interior structure is also beneficial to the building's seismic behavior.
\end{abstract}

Keywords: masonry building, steel frame, retrofit, seismic behavior, strengthening

\section{Introduction}

In old traditional masonry buildings the floors, the roof and sometimes the interior walls were made of wood. Many of these buildings were left without maintenance resulting in destruction of the wooden parts and leaving masonry walls standing either alone or connected with other exterior cross walls (Fig. 1). These remains of the masonry buildings have low resistance to lateral loads and may not survive future earthquakes. They can either be left in their present form but strengthened to survive lateral loads or can be used as part of a new structure that can be built inside the wall shell to bear vertical and lateral loading.

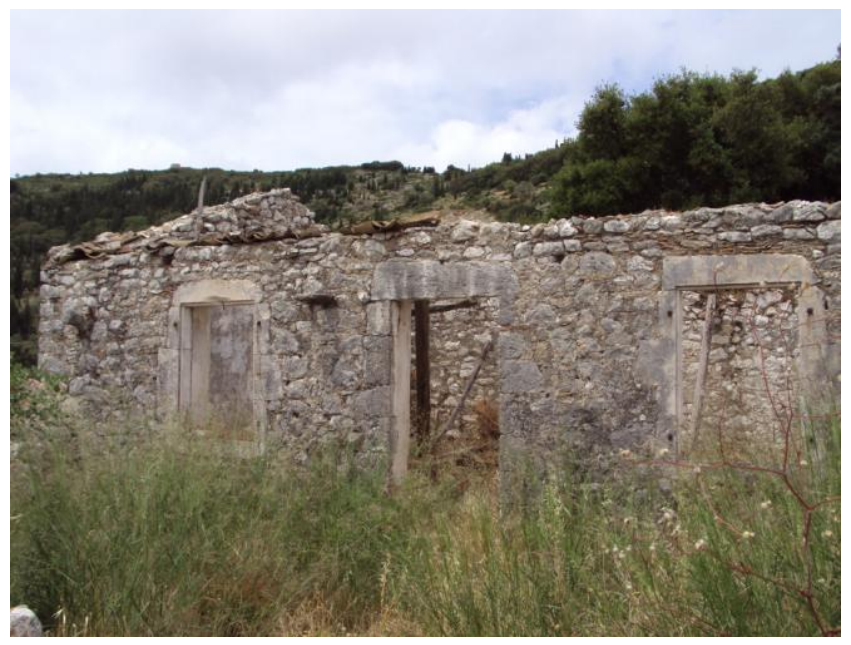

Fig. 1: Remains of a masonry building.

There are several methods that can be used to repair and strengthen masonry buildings or isolated walls [1]. These methods include the repair of the damaged part of the existing masonry walls (filling cracks, substituting damaged units, etc) and the addition, if needed, of new ones reestablishing the structure in its initial form without offering additional strength to the building (often required considering the today's building codes), the use of external post-tensioning with steel ties or composite tendons $[2,3]$, the use of concrete to increase the strength of the perimeter walls and the 
construction of interior frame from reinforced concrete to bear the loads, etc. Most of the times, these methods increase the stiffness of the structure moving its response to the first branch of the design spectrum and to smaller response values. This approach is more convenient and economical than increasing the flexibility of the masonry structures (moving their response to the right portion of the design spectrum and to smaller response values).

The use of steel frame systems to bear the loads is one of the most popular methods. The steel frames can be connected or not with the masonry walls (Fig. 2). This method has several advantages. It is reversible keeping the walls in their original form. This is highly desirable especially if the structure is historical and the interventions must follow the directions of the Charter of Venice [4]. If the walls are connected with the steel frames (the benefits of these connections will be investigated in this paper) only small areas in the inside part of the perimeter walls will be modified from their original form. In addition the steel frames can be erected fast and can give an additional strength to the walls of the building that have survived through the years.
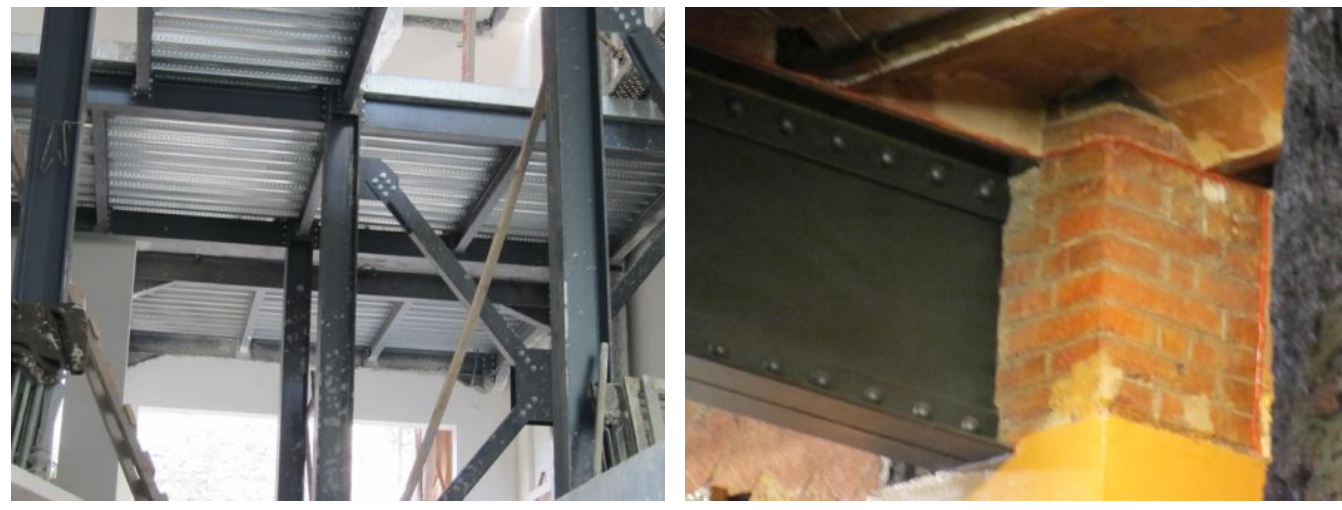

Fig. 2: Strengthening of masonry buildings using steel frames.

Previous studies have mainly focused on the structural characteristics and modeling of traditional and historical buildings [5, 6, 7, 8] as well as assessing their damage induced by earthquakes [9, 10]. Karantoni and Sarantitis [11] showed that the connection of the concrete or steel frame to masonry walls every $2 \mathrm{~m}$ at the floor levels creates a diaphragm which decreases the bending and increases the shear.

The use of steel frames to create a new structure inside an existing masonry building shell to bear the loads of the new floors or roof needs to be examined more closely. There are times that designers avoid contact of the wall with the steel frame columns and there are other times that there is a close contact between them (Fig. 2-3). There is a need for additional information about the seismic behavior of this composite structure.

This paper investigates the seismic behavior of masonry structures connected with steel frames. Several cases are considered including the investigation of the seismic behavior of an isolated masonry wall strengthened with a steel frame and the seismic behavior of a two story masonry building shell with a steel frame inside its perimeter walls to bear the loads of the floors. The behavior of this composite structure in relation of leaving a small gap between the steel frame columns and the walls (Fig. 3) is examined.

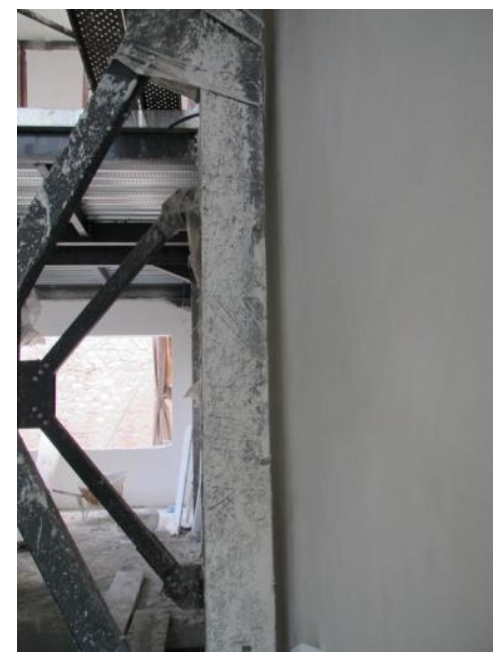

Fig. 3: Gap between steel frame and masonry wall. 


\section{The structural system}

The seismic behavior of a load bearing steel frame structural system connected with the existing walls of a masonry structure is analyzed. The investigation includes: a) a single masonry wall, b) a single story masonry structure consisting of its perimeter walls without openings, and c) a two story building consisting of its perimeter walls with openings.

The masonry walls are considered homogeneous based on Eurocode 6 equations [12]. The assumed homogenized properties of the masonry walls and dimensions are typical for old traditional stone buildings. The following properties are used: the thickness of the stone wall is $60 \mathrm{~cm}$, the density $2,100 \mathrm{~kg} / \mathrm{m}^{3}$, the modulus of elasticity $2,500 \mathrm{MPa}$, the compressive strength $2.8 \mathrm{MPa}$, the tensile strength $0.28 \mathrm{MPa}$ (assumed $10 \%$ of compressive strength), and the Poisson's ratio 0.24 . Two different sets of properties are used for the steel frame system corresponding to properties of commonly used I-section members. The first one consists of members with density $7,852 \mathrm{~kg} / \mathrm{m}^{3}$, modulus of elasticity $210 \mathrm{GPa}$, having cross sectional area $198 \mathrm{~cm}^{2}$, and moments of inertia $57,680 \mathrm{~cm}^{4}$ and $10,820 \mathrm{~cm}^{4}$. The second one consists of members with the same density and modulus of elasticity, having cross sectional area $270 \mathrm{~cm}^{2}$, and moments of inertia $171,000 \mathrm{~cm}^{4}$ and $13,530 \mathrm{~cm}^{4}$.

All the structural systems considered are fixed at the base and are analyzed for gravity loads and seismic actions. The gravity loads include a portion of live loads (when floor or roof is added to the structure). The seismic action is applied at different directions. The direction that produces the highest stresses is presented in this paper.

The seismic response of the structure is obtained using response spectrum analysis. The design spectrum used (based on Eurocode 8 [13]) is shown in Fig. 4. The behavior factor is assumed equal to 1.5, corresponding to a low ductility system, and the maximum design spectral acceleration equal to $0.48 \mathrm{~g}$ corresponding to areas of medium seismicity. The seismic response of the structures is evaluated performing linear elastic analyses using the structural analysis software ANSYS. The masonry walls and floors or roof are modeled using four-node quadrilateral shell elements having both bending and membrane capabilities, and the steel frame members using three dimensional beam elements. Special care is given in modeling the connections of the frame with the masonry walls. These connections are considered as hinges not allowing the transfer of the bending moment. A combination element that can be constrained with different flexibilities is used to describe the connections of the steel frame and masonry wall.

The results are presented in the form of contour plots of the principal tensile stress (in Pa) using the Square Root of the Sum of Squares (SRSS) method. The Complete Quadratic Combination (CQC) method is also used to validate the findings whenever the successive natural frequencies are close [14].

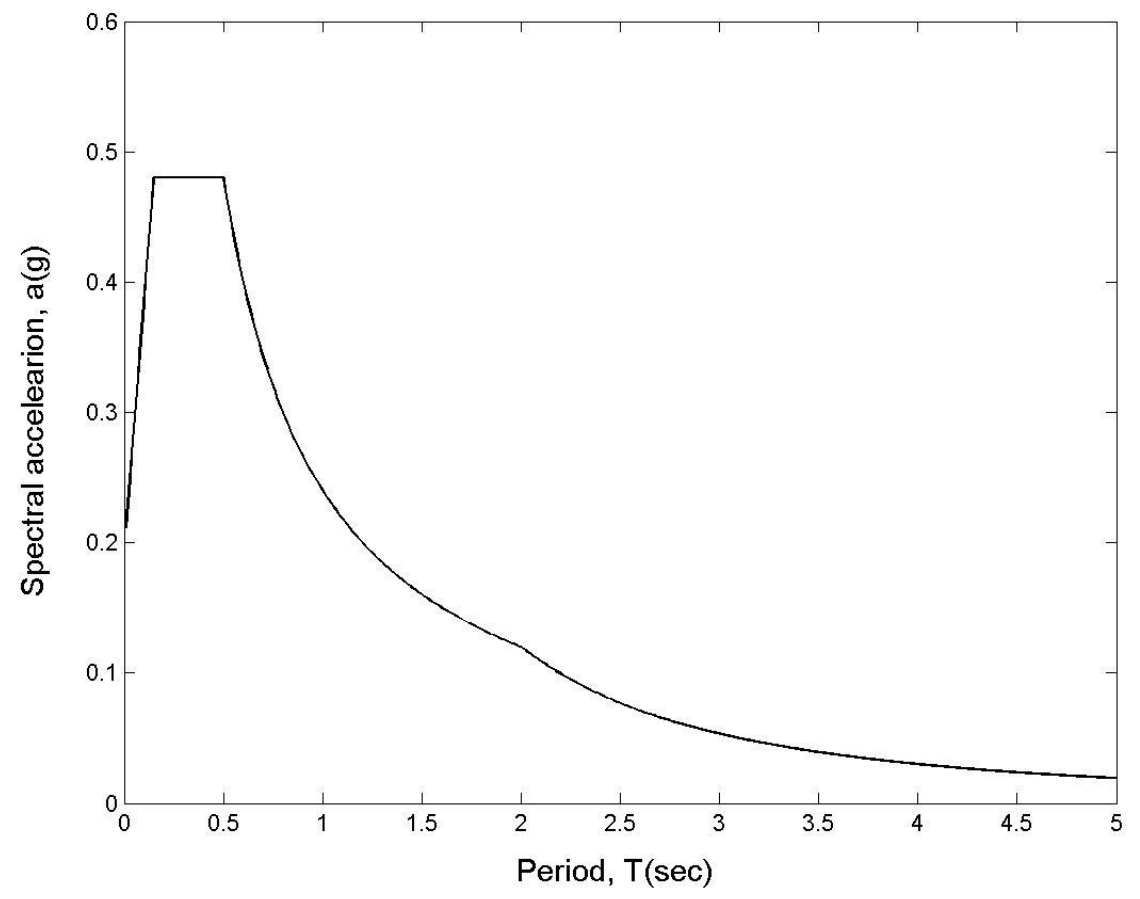

Fig. 4: Design spectrum for elastic analysis. 


\section{The seismic behavior of the system}

\subsection{Single wall}

At first, the seismic response of a single isolated masonry wall is examined. The dimensions of the masonry wall are $8 \mathrm{x}$ $6 \times 0.6 \mathrm{~m}$. Initially modal analysis is performed and the natural frequencies of the wall are identified. The first three natural frequencies of the wall are presented in Table 1. Next, spectrum analysis is performed using the design spectrum of Figure 4. The direction of the excitation is perpendicular to the direction of the plane of the wall. Fig. 5(a) presents the principal tensile stress developed in the wall. The maximum stress occurs at the base of the wall exceeding the wall's tensile strength. The stress is reduced gradually with the height of the wall. The displacements are increasing gradually from the bottom of the wall reaching their maximum value at the top $(3.7 \mathrm{~mm})$. The results indicate that the wall needs strengthening to survive the earthquake loading considered.

Table 1: Natural frequencies of structural system

\begin{tabular}{lccc}
\hline Structural System & $1^{\text {st }}$ freq. $(\mathrm{Hz})$ & $2^{\text {nd }}$ freq $(\mathrm{Hz})$ & $3^{\text {rd }}$ freq. \\
\hline Single wall & 6.776 & 10.621 & 20.257 \\
Perimeter walls & 11.821 & 12.735 & 15.443 \\
Two story building & 10.360 & 10.692 & 15.422 \\
\hline
\end{tabular}

Table 2: Natural frequencies of structural system after connection of frame with the walls

\begin{tabular}{lccc}
\hline Structural System & $1^{\text {st }}$ freq. $(\mathrm{Hz})$ & $2^{\text {nd }}$ freq $(\mathrm{Hz})$ & $3^{\text {rd }}$ freq.(Hz) \\
\hline Wall connected with frame at two places (frame set 1) & 7.752 & 12.097 & 17.085 \\
Wall connected with frame at several places & 10.938 & 14.995 & 24.382 \\
Perimeter walls connected with frame & 14.721 & 15.096 & 15.913 \\
Two story building with frame (connection at several places) & 10.765 & 15.580 & 18.424 \\
\hline
\end{tabular}

A steel frame (frame set 1), consisting of two columns and a beam, is added and connected to the top of the wall in two places at the junctions of the column and beam of the steel frame and the corresponding node of the wall opposite of the junction. The columns are located in near proximity to the two ends of the wall. The same properties are used for all frame elements. The natural frequencies increase (Table 2) and the seismic response of this composite structure is reduced. The principal tensile stress is reduced approximately by $26 \%$ at the bottom of the wall. The overall displacement also is reduced to a maximum value of $2.85 \mathrm{~mm}$ occurring at the top of the wall. Even though the principal tensile stress and the displacement are reduced the principal tensile stress exceeds the wall's tensile strength at a substantial area at the lower part of the wall so a better connection scheme is needed.

Different schemes for connecting the frame with the wall have been considered. It is found that the frame must be connected with the wall not only at the ends of the wall but also in the middle. Thus, an additional steel column is added to the frame to achieve its connection with the wall every 3 to $4 \mathrm{~m}$. The best connection scheme that reduces the wall's response below its tensile strength is achieved when the three frame columns are connected with the wall every $1 \mathrm{~m}$. In addition the stiffer frame (frame set 2) increases the natural frequencies of the wall-frame system (Table 2) and reduces the response to values well below the wall's tensile strength (Fig. 5b). No additional connection of the beam is needed with the wall except at the top of the columns. The displacement also is reduced to lower values with the maximum appearing at the top $(1.34 \mathrm{~mm})$.

\subsection{Perimeter walls}

The case of the remaining shell of a masonry building is considered assuming the existence of walls in an orthogonal perimeter $8 \times 6 \mathrm{~m}$. The walls are without openings. The seismic behavior of this structural system is investigated initially without any strengthening. Modal analysis is performed and the natural frequencies are calculated (Table 1). This structural system is excited with the same excitation as before (Fig. 4). Its response in the form of contour plots of the principal tensile stress (Fig. 6a) indicates that the maximum stress occurs at the low middle part of the walls that are located perpendicular to the direction of the excitation (long walls) exceeding the tensile strength of the walls. High stresses occur also at the top junctions with the cross walls as well as at the top middle of the long walls. The walls that are located parallel to the direction of the excitation (short walls) are in low stress except at the top junctions with the cross walls.

In the next case, a steel frame is considered inside the walls. The steel frame is attached in different ways to the walls based on the conclusions of the first part of this investigation. Low values of the principal tensile stress occur when the 
second frame set is used. The natural frequencies of this composite structure are higher than the previous case (Table 2). Using the same excitation as before, it can be noticed that high stresses occur at the top junctions with the cross walls as well as at the middle low part of the long walls (Fig. 6b). All stresses though are well below the tensile strength of the walls. The maximum principal tensile stress that occurs at lower middle part of the long wall is reduced by $27 \%$.

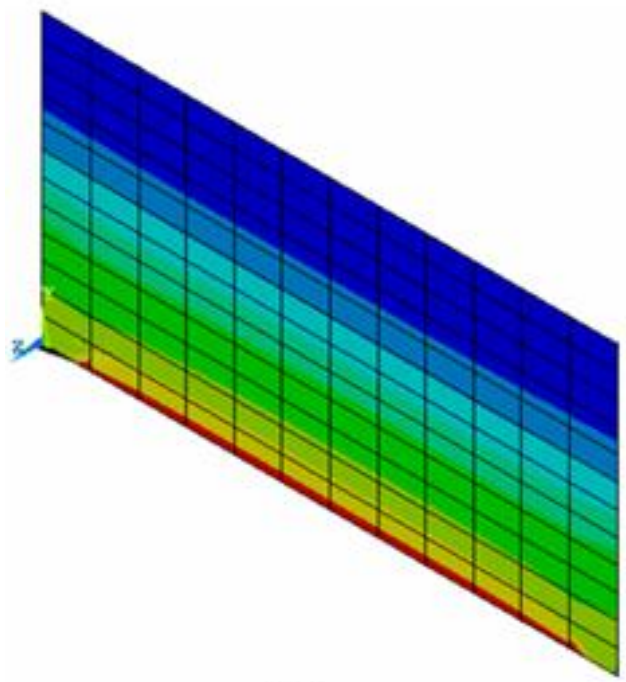

(a)

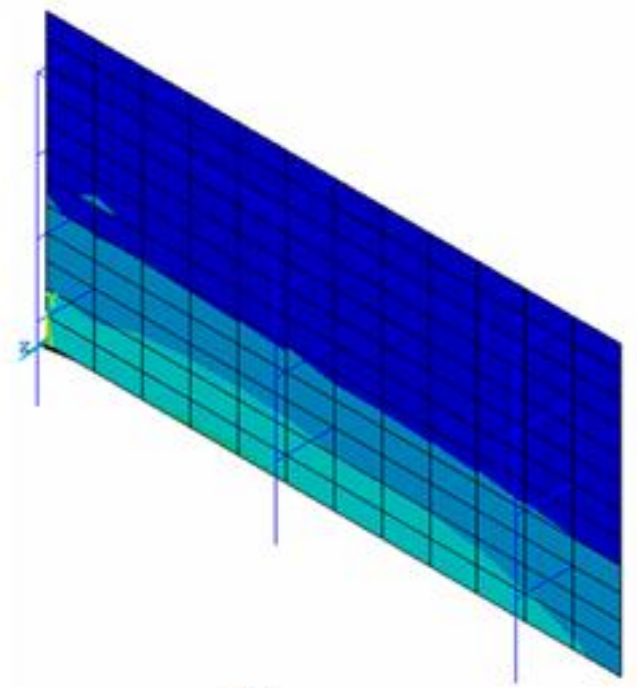

(b)

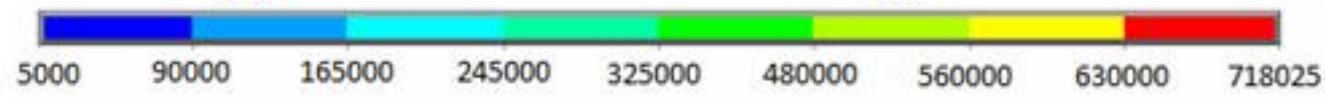

Fig. 5: Principal tensile stresses (in Pa) developed in (a) isolated masonry wall; (b) wall connected with steel frame at several places

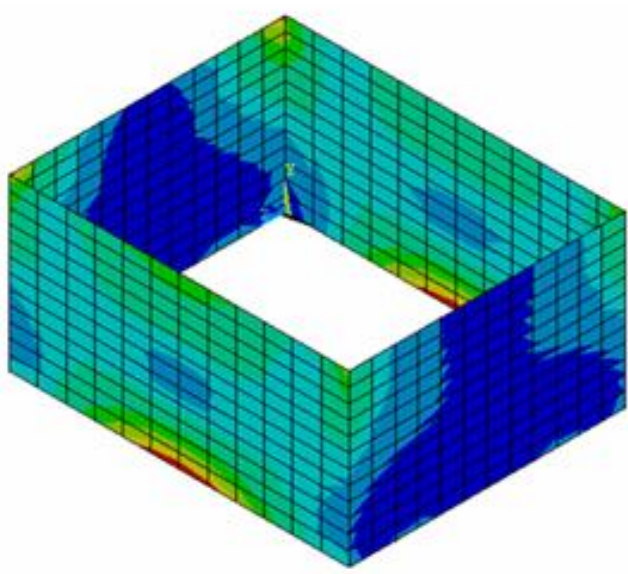

(a)

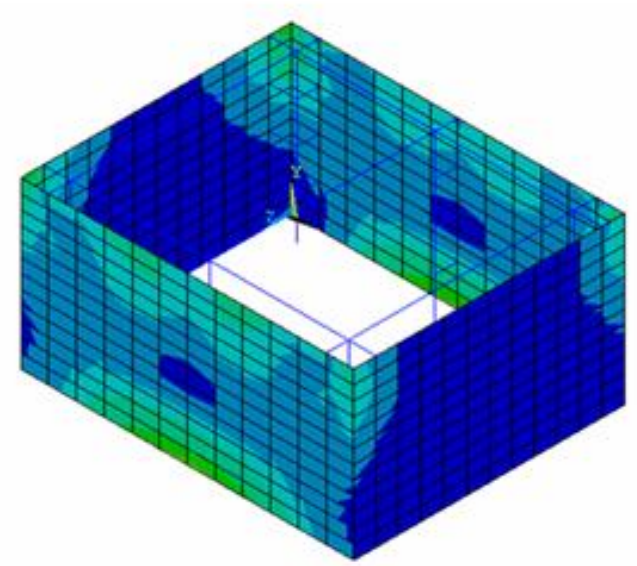

(b)

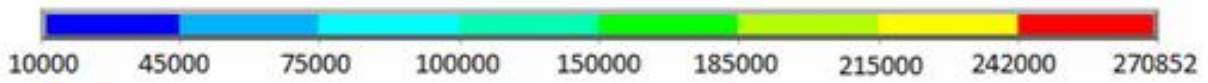

Fig. 6: Principal tensile stresses (in Pa) developed in the (a) masonry walls of one story structure; (b) masonry walls, connected with steel frame, of one story structure. 


\subsection{Two story building}

Similar connection schemes of the steel frame and walls are considered for a structural system consisted of the shell of a two story building with openings (windows and doors). A steel frame (second set) inside the walls supports concrete slabs with the following properties (commonly used for concrete slabs): thickness $17 \mathrm{~cm}$, modulus of elasticity 28.85 $\mathrm{GPa}$, density $2548.5 \mathrm{~kg} / \mathrm{m}^{3}$, Poisson ratio 0.2 and compressive strength $20 \mathrm{MPa}$. A surface load of intensity $2.5 \mathrm{kN} / \mathrm{m}^{2}$, corresponding to additional dead load and a portion of live load, is applied at the slabs. Initially, the frame is not connected with the walls but only with the slabs. Modal analysis is performed to calculate the natural frequencies of the system (Table 1). In continuation the seismic response of the building is obtained for the same excitation used earlier. The highest stresses occur at the floors but they are below concrete's tensile strength. The highest stresses at the walls occur at the first story and especially at its two low corners of the long walls exceeding their tensile strength (Fig. 7a). High stresses exceeding the tensile strength of the walls occur also around the windows of the short walls.

Different connection schemes of the steel frame and the walls are used. The one that gives low values of stresses resembles the ones used for the single story perimeter walls (connection of the frame columns with the walls at every meter) except that it is needed diagonal bracing (frame set 2) not only close to the short length walls but also in the middle obtaining diagonal bracing approximately at every $3.5 \mathrm{~m}$. The first natural frequencies increase (Table 2) and the seismic response reduces to lower values than the tensile strength of the walls (Fig. $7 \mathrm{~b}$ ).

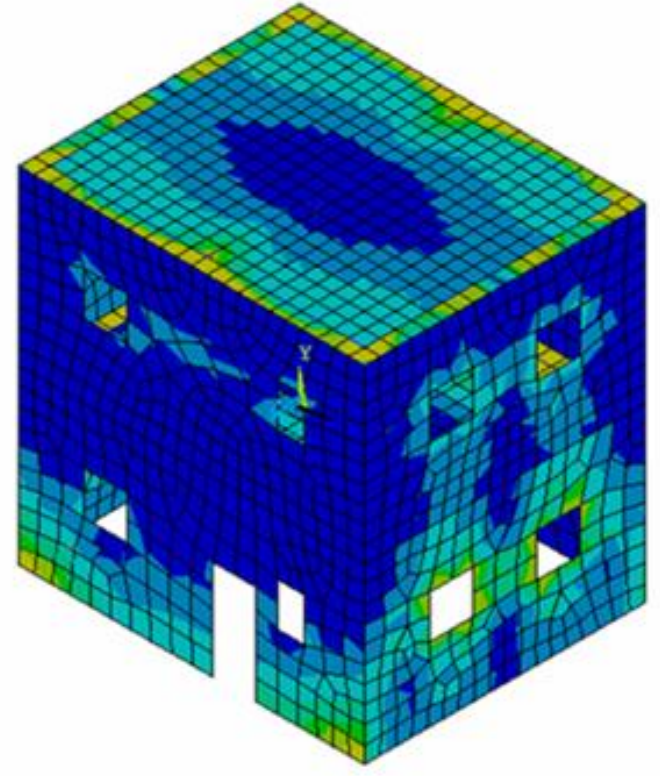

(a)

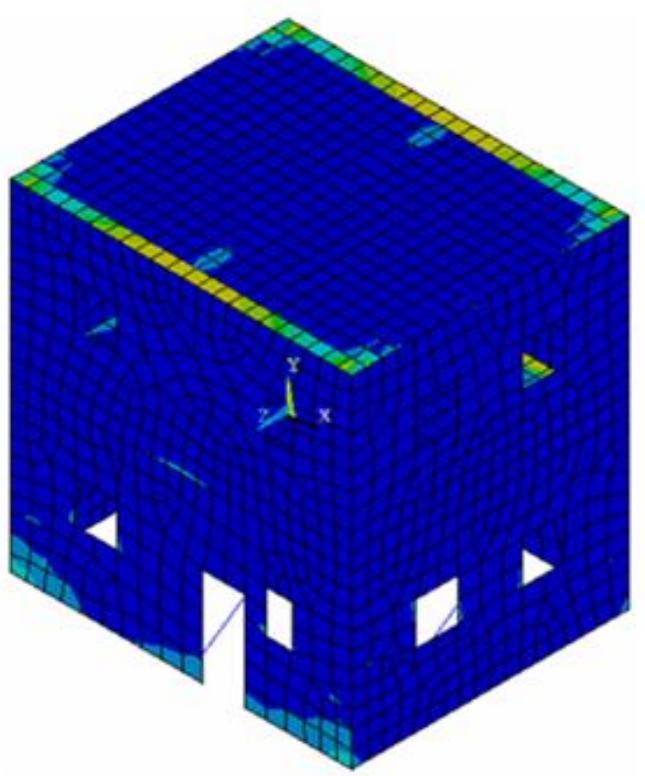

(b)

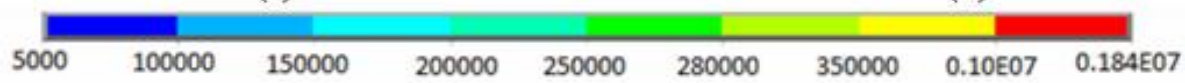

Fig. 7: Principal tensile stresses (in Pa) developed in the (a) walls of a two story building; (b) walls of a two story building connected with steel frame.

\section{Conclusions}

Several methods are available for the strengthening of masonry structures to withstand earthquake loading. One of the methods that increase the stiffness of the masonry structure, reduce its seismic response, without altering the original form of the walls (but only at small areas) and keeping its reversibility is investigated in this paper. This method is based on the connection of the masonry walls to steel frame systems. The steel frame systems are used either to strengthen and support the masonry structure to lateral loading or to create a new structure inside or next to the masonry remains.

The seismic behavior of the masonry-steel frame structure improves when there is a close space connection of the steel columns with the walls instead of leaving a gap between the steel frame column and the walls. In particular, the frame columns must be spaced every three to four meters and connected with the masonry walls every one meter. It is also beneficial to the structure, when applicable, the floors and roofs to be connected not only to the steel frames but also to 
the masonry walls. As the flexibility of the remains of the masonry structure increases (for example for tall structures) the stiffness of the steel frame has to increase. This can be accomplished using stiffer steel members with the addition of diagonal bracing approximately at every three to four meters.

\section{References}

[1] A. Newman, "Structural Renovation of Buildings", McGraw Hill, NY, 2001.

[2] K. Bohn, "Strengthening of Pisa Tower by external post-tensioning", Structural Preservation of the Architectural Heritage; Proceedings of OABSE Symposium, Rome, 1993, pp. 715-716.

[3] T. C. Triantafyllou, and M. N. Fardis, "Strengthening of historic masonry structures with composite material", Materials and Structures, Vol. 30, 1997, pp. 486-496.

[4] Charter of Venice, "Decisions and resolutions", Proceedings of the 2nd International Congress of Architects and Technicians of Historical Monuments, Venezia, Vol. 5, 1964, pp. 25-31 [in French].

[5] F. V. Karantoni, and M. N. Fardis, "Effectiveness of seismic strengthening techniques for masonry buildings", Journal of Structural Engineering, Vol. 118, 1992, pp. 1884-1902.

[6] P. Rosa, M. Cervera, G. Gariup, and L. Pela, "Structural analysis of masonry historical constructions. Classical and advanced approaches", Arch Comput. Methods Eng., Vol. 17, 2010, pp. 299-325.

[7] E. Teomete, and E. Aktas, "Structural analyses and assessment of historical Kamanli Mosqu in Izmi, Turkey", Journal of performance of constructed facilities, 2010, pp. 353-364.

[8] E. Vintzileou, A. Zagkotsis, C. Repapis, and Ch. Zeris, "Seismic behaviour of the historical structural system of the island of Lefkada, Greece", Construction and Building Materials, Vol. 21, 2007, pp. 225-236.

[9] F. V. Karantoni, and M. N. Fardis, M. N., "Computed versus observed seismic response and damage of masonry buildings", Journal of Structural Engineering, Vol. 18, 1992, pp. 1804-1821.

[10] F. V. Karantoni, and G. Bouckovalas, "Description and analysis of building damage due to Pyrgos, Greece earthquake", Soil Dynamics and Earthquake Engineering, Vol. 16, 1997, pp. 141-150.

[11] F. Karantoni, and D. Sarantitis, "Seismic behaviour of masonry buildings after alterations of the load bearing system", 3rd National Conference in Seismic Mechanics and Technical Seismology, November, Athens [in Greek], 2008.

[12] European Committee for Standardization, "Eurocode 6: Design of masonry structures", CEN, Brussels, Belgium, 1996.

[13] European Committee for Standardization (1994). "Eurocode 8: Design of structures for earthquake resistance", CEN, Brussels, Belgium, 1994.

[14] B. P. Leftheris, M. E. Stavroulaki, A. C. Sapounaki, and G. E. Stavroulakis, Computational Mechanics for Heritage Structures, WIT Press, UK, 2006. 